\title{
The Cyber Balkanization and Structural Transformation of the Public Sphere in Korea
}

\author{
Chang Woo-young *
}

The development of information and communication technologies (ICTs) has supported improvements in political communications among citizens, the organization of civil society groups, and collective action among citizens. Such changes are contributing to the re-vitalization of the public sphere. The public sphere, which is a tremendously broad physical and symbolic space where public opinion is created, is composed of communication structures of a society. Furthermore, the distribution structure of communication reflects the social relationship of power and leads to fundamental changes in the roles and functions of actors as well as their relationship (Bimber, 2003; Newhagen \& Levy, 1996; Fraser, 1992). In mass media-based communication, citizens have hitherto remained in the status of passive information recipients. But today's web-based communication fostering a number of noticeable changes in the structure of information distribution including the breakdown of the boundary between information producers and recipients, obsolescence of gatekeeping, and promotion of interactive media modes. Thanks to such changes, citizens can now proactively participate in public discussion activities.

The functions and innate structure of the public sphere undergo changes under the intervention of the social context. According to Habermas (1989), the dynamics of the formation and restructuring of the public discussion forum can be conceptualized as "the structural transformation of the public sphere." Since the 1990s, Korean society has expanded the cyber public sphere amid the development of the new media including PC communication, the Internet, and mobile communication. By reforming the mechanism of agenda setting and public opinion, the cyber forum for public discussion has demolished the monopoly of the mass media-based public sphere. Furthermore, the use of the cyber forum for public discussion as a tool for political mobilization and social movement has caused profound political ramifications. In the process, the progressive camp has taken ideological initiative and reaped political fruits. Therefore, the progressive camp has been perceived as the principal beneficiary of the changes in the cyber space. Recently, however, conservative camp has made a great leap forward in cyberspace and begun to carry out countervailing public discussion activities. As a result, it has become questionable to equate the Internet as an abode reserved only for the progressives. The Internet has become the locus where fierce ideological competition is taking place. In short, the topography of power in the cyber forum for public discussions is undergoing a restructuring as a more power-balanced system is emerging from the previous structure dominated by the progressive camp.

The goal of this paper is to identify the causes of the formation and restructuring of the cyber public sphere and to assess their political implications in Korea. Historically, the public sphere is a product of political enlightenment and social environment created by modernization. And the advent of new types of media and antagonism among communication actors has caused structural changes in the public sphere. With

\footnotetext{
* Chang Woo-young is Professor of International Administration at Catholic University of Daegu (changwyng@yahoo.com).
} 
this goal in mind, this paper begins with an analysis and review of the formative periods of cyber forums for public discussion and the evolution of cyber initiatives led by the progressive camp in Korea. Then, the restructuring of the cyber public sphere caused by great advances made by the conservatives is examined. Finally, instead of a conclusion, great cyber leap forward of conservatives is evaluated and its implications are assessed. This case study centers on Korean case and is expected to contribute to cross-national studies on the evolution of cyber public sphere by providing a number of meaningful factual and theoretical observations for comparison. The two main methods used in this study are participatory observation in major websites and analysis of various types of quantitative data.

\section{Theoretical Perspective:}

\section{The Formation and Realignment of the Political Forum for Public Discussion}

\section{The Opening of the Public Sphere and the Participation of Citizens}

The public sphere is an independent and autonomous space for public communication in which interacting citizens freely participate in rational argumentation and actively create competitive public opinions. Habermas (1989) and Arendt (1998) emphasize the importance of the public sphere as a political tool used by citizens in their daily life. In other words, the public sphere is the route of citizens' political participation in which open politics of public opinion is realized. Therefore, autonomy, openness, and interactivity are the essential components of the public sphere. By actively participating in such public activities, citizens are reborn as the responsible public and can establish the counter-hegemony of civil society against the ruling groups.

The public sphere builds a boundary between the state and the society as "a realm of tension" and pursues "the communicative rationality and autonomy" of civil society. As essential parts of the public sphere, today's various associations and the media play the roles of counterbalancing and monitoring state power and conveying the interests and demands of civil society to the state or the political society (Yun Pyeong-jung, 2003; Jang Myeong-hak, 2003). Various political functions of the public sphere are derived from the establishment of "the communicative power" led by citizens. In particular, the capacity for "bottom-up agenda-setting and public opinion formation" through citizens' interactive communication is the pillar of communicative power. Such expansion of the civil society's autonomous public sphere unlocks the democratic potential (Poster, 1997).

A word of caution is that the public sphere does not refer to a single and uniform world of communication. Keane (2000) and Davis (1999) noted that a large number of communication spaces, in other words a multiplicity of public spheres, have appeared and these are breaking the existing public sphere, which is spatially integrated within the framework of the nation-state. In effect, the public sphere in contemporary society is undergoing segmentation caused by "diversification of communication actors and the media." Habermas defines citizens as actors that put forward the demands of the civil society to the state in accordance with the ideology that purports to make the political power rational. Depending upon their interests, preferences, and needs, citizens are divided into various types of factions. Accordingly, individuals and groups that pursue common interests and goals establish public spheres divided by partisanship. Even in the case of public communication, re-strengthening of homo- 
geneous opinions rather than efforts for convergence and coordination of heterogeneous opinions has become a deepening trend (Negt \& Kluge, 1993; Norris, 2002).

The media can be understood as a tool that promotes multi-layered fragmentation of public spheres. For instance, the mass media creates communicative hierarchy by gate keeping and by delineating the boundary between the information producers and information recipients. Moreover, the established media-politicized and commercialized - has been criticized for filtering and excluding diverse social demands by monopolizing the processes of agenda-setting and message production. Dahlgren (1995) conceptualizes such a "hegemonic public sphere" as "the common domain." In contrast, the public that are alienated from the existing media create an "alternative public sphere" where they can disseminate their arguments. The alternative forum is what Dahlgren conceptualizes as "the advocacy domain." The public that promote the alternative forum share their group identity and pursue political goals through smallscale media such as wall-posters, local radio stations, and the Internet, which are less demanding in terms of resources and costs.

\section{The Structural Transformation of the Public Sphere}

Habermas uses the expression "structural transformation of the public sphere" to explain the changing nature of the public discussion forums under the impact of diverse social factors. From the political perspective, this refers to the reorganization of communicative power within society. More specifically, the transformation is occurring in two dimensions: (1) vitalization or degeneration of the "function" of the public sphere and (2) the change in "political topography" inside the public sphere. Regarding the first dimension, Habermas argues that "re-feudalization of the public sphere" is caused by the alienation of citizens from the realm of politics under the influence of the concentration of capital and the expansion of state, the emergence of mass society, bureaucracy and interest groups, factionalization of political parties, and the media that have become large corporations. Habermas is thus pointing to the fact that the mass media in the contemporary society can no longer play the function of fostering interaction and rational discussion among citizens. The incompetence of the mass media is caused by their being closely adhered to political power or excessive commercialism. Such explanation is based on functional change of the public sphere. In contrast, Habermas also emphasizes changing power configuration inside the public sphere as an important aspect of the structural change. According to Habermas, public discussion activities are political behaviors that accompany exchange of and competition among diverse values and opinions. Therefore, tension and conflict among ideological groups remain inside the public sphere. In addition, power configuration inside the public sphere can be changed by active challenges against dominant ideology or communication groups. Such structural change is mainly caused by a sense of political crisis and reaction inside the public sphere (Habermas, 1989).

Recently, the expansion of the cyber public sphere and competition among ideological groups has dynamically shown different aspects of the structural change of the public sphere in contemporary society. Historically, the Internet is the most expression supportive and citizen-centered media. Furthermore, the Internet provides a space for broad communication and has gradually changed the axis of the public sphere from the offline to the online world (Boncheck, 2005; Kellner, 2001; Schultz, 2002). This phenomenon corresponds to the functional dimension of the structural change in the public sphere, which was explained by Habermas. Likewise, in the case of Korean society, the cyber public sphere has rapidly expanded since the mid-1990s whereas 
the politicized and commercialized mass media has lost its role of providing the public sphere. In particular, the progressive camp has taken the initiative in cyberspace by using various types of online media including PC communication communities, closed user groups (CUGs), independent Internet newspapers, political webzines, portal sites for social movements, fan clubs sites of political leaders, and "anti" sites (See Chang, 2005a). In the case of the United States, conservative online initiatives have become stronger thanks to more efficient use of Internet newspapers, political webzines, and political salons. The conservatives' use of new media takes the form of counterattacks against progressive media sources (Viguerie \& Franke, 2004).

More interestingly, power configuration change within the cyber public sphere is accelerating. Korea's progressive camp, which has used the Internet as a means of alternative journalism and social movement, has preemptively set the political agenda in cyberspace and has successfully carried out cyberactivist strategies. Recently, however, the advances of the conservative camp in the cyberspace have become pronounced. As a result, the power configuration in the public sphere is changing from the predominance of the progressive camp to a more balanced configuration. In particular, new conservative websites have appeared and the existing ones have become more active since March 12, 2004 when the opposition parties attempted to impeach President Roh Moo Hyun. In the United States, the progressive camp has attempted counterattacks against conservative initiatives. For instance, American Civil Liberties Union (ACLU) and Electronic Frontier Foundation (EFF) have carried out 'counterattack' against conservative initiatives. In the political world, presidential candidates of the Democratic Party including Al Gore and Howard Dean actively used the cyberspace. However, according to Viguerie and Franke (2004) who monitored changes in the ranking at alexa.com, conservative websites' unique and page view are increasing more in cyberspace since 2004 and a turn to the right has occurred. ${ }^{1}$

The structural change in the cyber public sphere is interpreted as an "ideological normalization." In other words, ideological predominance in cyberspace is being replaced by a system of balance between the two ideological camps. Moreover, the normalization is comparable to "contagion from the left," which characterized changes in Western political party systems. Habermas's explanation - the power configuration inside the public sphere is changed under the impact of the challenge from the underdog ideological group - is especially useful. Normalization progresses with the conservative camp's nurturing of a sense of political crisis and the learning effect. During the industrial age, some latecomers could achieve success by learning from the weaknesses and strengths of previous models. Similarly, the conservatives are taking advantage of "the advantage of backwardness" as the cyber public sphere undergoes ideological normalization. By integrating the experiences of the progressive camp, the conservative camp is expanding their political influence in the cyberspace. The structural change takes the form of position warfare in which ideological groups strive to gain hegemonic status in cyberspace. Because cyberspace is a space of unlimited opportunities and possibilities, the re-structuring of cyber public sphere will evolve in an extremely dynamic fashion. 


\section{The Evolution of the Cyber Public Sphere during Period of Progressive Preponderance}

\section{The Formative Phase Based on PC Communication}

In the age of informatization, cyberspace is an arena of competition where social forces are engaged in hegemonic struggle to establish new values, norms, and order. In this struggle, the challenge of the civil society to expand democratic possibilities assumes enhanced importance. In the last ten years, Korea's progressive camp has strategically used the Internet to launch initiatives in the cyber public sphere. Thanks to these initiatives, the excitement surrounding debates on progress that accompanied the democratic transition ${ }^{2}$ could widely spread throughout the cyberspace. Because of the enthusiasm engendered by initiatives, the progressive camp achieved remarkable successes in major elections and social movements.

What was the process by which the progressive camp could occupy the cyber public sphere? First, the progressive camp played a leading role in exploiting the new "political opportunity structure." The advancement of informatization ${ }^{3}$ functioned as a factor that supported the strategies of cyberactivism adopted by the progressive camp, which has historically led social movements in Korea. Trevor (1999), Meikle (2002), McCaughey and Ayers (2003), and Kahn and Kellner (2004) argue that technological tools such as the network and the new media form core elements in the political structure of opportunities in the age of informatization. In the domain of social movements, the Internet provides strategic tools such as the following: (1) low-cost participation, (2) multi-layered methods of participation that include access to political information, expression and exchange of opinions, the formation and operation of organizations, and collective action, and (3) collective identity of participants and a sense of political effectiveness (Schmidtke, 1998; Corrado, 1996). In fact, informatization does not favor specific groups as it can benefit any group that actively exploits it. The Korea's progressive camp was the first to take advantage of the potentials of informatization. The progressive camp employed the Internet to organize a number of eventful movements: campaigns against the conservative media, anti-American candlelight demonstrations, electoral campaigns to prevent party candidate nominations and the election of opposition politicians, Nosamo activities, campaign to oppose impeachment of President Roh Moo Hyun, etc. (See Chang, 2005a; 2005b; 2006a; $2006 \mathrm{~b}$ ). The use of the Internet in the mass mobilization and social movement of the progressive camp, which symbolizes the 2000 s, was a significant factor that influenced the progressive dominance of the cyber public sphere.

Second, the "alternative media movement" has challenged the existing public sphere, which is based on the mass media. Criticism has been leveled at the mass media because they have represented the interests of the privileged groups and filtered inimical public opinions although they have the capability to mass produce and transmit messages. It is from such context that the progressive camp led in the 1980s a movement to refuse payment of television subscription fees to Korean Broadcasting System (KBS), a public broadcasting company. Furthermore, the camp pursued the founding of progressive magazines and newspapers. In the 1990s, the camp launched a movement for the reform of the media, which was symbolized by the anti-Chosun Ilbo movement. However, because a conservative media cartel dominated the media market, the progressive camp opted to explore the rich political resource of the Internet. The alternative media, which were rooted in small-scale PC communication communities and irregularly published current affairs webzines, began to develop the 
cyber public sphere. Their use of Internet newspapers and political webzines was supported by widespread availability of access to the Internet. Likewise, the progressive camp extended the realm of the public sphere by creatively using online media entities including portal sites for social movements, fan club sites for politicians, and "anti" sites. In contrast, the conservative camp did not keenly feel the necessity to actively exploit the Internet because the mainstream media faithfully represented its interests.

Third, the progressive camp mounted a "campaign to oppose regulation on the Internet" to promote autonomous public discussion activities and subcultures. Traditionally, Korea has been dominated by authoritarian Confucian culture. The Confucian tradition restricted free expression of opinion and consolidated authoritarian values of hierarchy, submission, and patience. The process of democratization dissolved cultural authoritarianism and spread pluralist culture throughout society. In the cyberspace as in the real world space, the "spiral of silence," which refers to suppression of minority voices and their assimilation into majority voices, is attenuated. The waves of pluralism rippled further in cyber space and nurtured autonomous public discussion activities and subcultures. In particular, young netizens, who can competently use ICTs and are highly culture sensitive, have turned the Internet into "a competitive market of ideas and cultures." However, tension in cyberspace intensified because national network policy changed from laissez-faire to regulation. The system of Internet regulation in Korea was strengthened by institutions including Korea Information Ethics Commission, etc., acts including Act on Promotion of Information and Communication Network Utilization and information Protection, and Telecommunications Business Act, etc., and regulatory devices including the Internet contents rating system and the real name system, etc. Responding to the tightening restriction, the progressive camp organized a group called Collective Action Against Censorship of Information Communication (noncensor.org) to aggressively pursue fundamental information rights including freedom of expression, sharing of information, and privacy (Chang, 2006a).

In Korea, the cyber public sphere began to be formed in the days of PC communication. Since 1998, bulletin board systems (BBSs) of progressive persuasions were established: Wall-paper (labor union of Daewoo Motors), Peacemaking (Grassroot Church), Communication for the Liberation of the Labor (Aricom). In the early 1990s, bulletin board systems for political discussions such as Hot Issue and Politics (KIDS, the KT Corporation), Acropolis (communication network of Seoul National University), Plaza (Hitel), Me talk too (Chollian), Public Opinion Plaza (Naunuri) were in active operation. The BBSs were famous media for discussing current issues. In the mid-1990s, progressive communities in commercial communication networks functioned as major communicatives space for progressive netizens. The most representative online progressives were Batongmo (Hitel), Hope Ground and Contemporary Philosophy Community, and Cold Spring (Naunuri) (Oh Byeong-il and Jang Yeo-gyeong, 2003; Yung Yeong-min, 1996). ${ }^{4}$

During this period, the seeds of the public sphere began to sprout. Most importantly, the non-gaek(polemists, 論客), leading mobilizers of the public opinion, began to appear. The non-gaek refers to "online journalists that generate progressive political discourses in cyberspace." They did not belong to any existing group of intellectuals but they led public opinion in PC communication as hundreds and thousands of readers read their columns. Subsequently, with the growth and spread of the Internet, the non-gaek participated in the alternative media movement and published political webzines (Chang, 2005b). Furthermore, cyberactivism emerged and exploited the 
network as a tool of social movement. The labor union of the KT Corporation in 1995 and the Federation of Korean University Students' Councils in 1996 established closed user groups (CUGs) in the PC communication network for internal communication to organize strikes and promote opposition to the government. On their part, progressive online communities organized permanent networks for social movements in cyberspace to cope with major social issues. Since the mid-1990s, the Information Communication Solidarity group has provided Internet hosting service to support solidarity among social movement organizations. The movement to oppose the government's attempt to apply restrictions to the Internet merged with the existing trends in the Internet. The progressive camp view was that Internet regulation would harm freedom of expression and social movements. True World BBS and the Information Communication Solidarity (inp.or.kr) were in charge of the movement, and they jointly established Progressivenet (jinbo.net) that later emerged as a social movement portal site for the progressive camp.

\section{The Expansion Phase Based on the Internet}

With the universalization of the World Wide Web, the Internet-based cyber public sphere entered an expansion phase. The most salient realms for public discussion activities on the part of the progressive camp are Internet newspapers, political webzines, and fan club sites of politicians. Ohmynews (ohmynews.com) emerged as the most influential Internet-based newspaper. Ohmynews has a large number of netizens as "citizen journalists" and abolished the border between producers and recipients of information (Oh Yeon-ho, 2004). As of 2007, 40,000 citizen journalists are registered with Ohmynews and the citizen journalists write 150 of 200 daily articles. Thanks to its open system of message production, Ohmynews could expose various types of issues. Ohmynews has functioned as an epicenter of social movements and political campaigns. For instance, massive anti-American candlelight demonstrations in 2002 were triggered by articles on the death of middle schoolgirls reported by Ohmynews. According to annual survey of Sisa Journal, Ohmynews was ranked the eighth (2001) and sixth (2003) most influential media in a list prepared by a panel of experts. In 2004, Ohmynews topped the list of media with greatest growth potential by a panel of experts organized by Media Today. ${ }^{5}$

Political webzines can be considered as the most creative media experiments carried out by the progressive camp. Even in the days of PC communication, the nongaek that are wildly popular among netiznes had appeared. Continued resentment toward the Chosun Ilbo was the common ground that united the non-gaek in cyberspace and led them to seek organization. Urimodu (urimodu.com) and Daejabo (jabo.co.kr) are the two major anti-Chosun Ilbo sites where the non-gaek were active. On these websites, reform of the media was the main issue for discussion and new non-gaek appeared with the evolution of the discussion. Seoprise (seoprise.com) was the first non-gaek site with specific political goals that was organized by the non-gaek during the sixteenth presidential election in 2002. At that time, the popularity rating of Roh Moo Hyun, the progressive camp's favorite candidate, was down to $10 \%$ and the Millennium Democratic Party was undergoing division. To reverse this tide, the nongaek who supported the party established Seoprise to carry out pro-Roh campaigns. Subsequently, Seoprise disseminated various arguments and strategies in cyberspace played that a leading role in drawing up a discussion agenda for critical issues of the presidential election campaign, including the issue of agreeing upon a single candidate against the Grand National Party (conservative). To support Roh, the nongaek wrote columns and netizens attached comments to them. The netizens also copied the non-gaek's columns and pasted them on the websites. Some active netizens 
gaek's columns and pasted them on the websites. Some active netizens became the non-gaek through a system of recommendation and peer review scoring system (Chang, 2005b). Seoprise has often been cited as the main factor that contributed to Roh's electoral victory.

Finally, the progressive camp organized the Nosamo (nosamo.org). ${ }^{6}$ The Nosamo exerted the most powerful political impact on Korea's last presidential election. The Nosamo is the prototype of fan club sites for politicians, which are currently booming in Korea. The organization may be a product of emotional fandom culture. More importantly, however, its significance lies in the following salient attributes: voluntary organization of the community, organized focus on public issues, and efficient political mobilization. Voluntariness and commitment shown by the Nosamo was truly exceptional considering that communities, which are organized around individual political interests and concerns, tend to be characterized by "weak tie" (Bimber, 1998). The Nosamo was radically different from Korea's heteronymous private organizations that support politicians. During the 2002 presidential election, the Nosamo achieved political success in the Millennium Democratic Party's presidential preliminary election, in which citizens could participate as voters, and the party's electoral campaign by implementing strategies aimed at actively mobilizing support through the online media. The success can be attributed to the fact that internally shared goal and autonomous participation worked to translate online communication into political action (Chang, 2006b). The transformation of the organizational characteristic of the Nosamo in accordance with the evolution of the political context accompanying necessity to change political goals, illustrate the characteristic of the Nosamo as a "strong tie." Although the Nosamo began as a fan club, the organization became a political association during the Millennium Democratic Party's presidential preliminary election, an electoral machine during the presidential campaign, and a politicized citizens' organization after the election (Kim Yong-ho, 2004).

The period ranging from the sixteenth presidential election until the opposition parties' attempt to impeach President Roh, was the period during which the progressive camp unequivocally dominated the cyber public sphere. The dominance was enabled by a strategy that maximized the online media effect. Depending upon their innate characteristics, the media can generate various levels of communication methods and effects. Because the Internet supports intensive interactions, it has the potential to empower netizens as actors that set agenda and form public opinion. The potential was fully unlocked in the Korean context. Ohmynews' system for selecting citizen journalists, Seoprise's non-gaek system, and the Nosamo experimentation with political fandom community can be counted as globally unprecedented cases. The websites are currently firmly established in Korea as conventional media and communicative tools for the cyber public sphere.

The well-established progressive media, which were positioned throughout cyberspace, could achieve political impacts by facilitating aggregation of netizens on an around-the-clock basis. Netizens' public discussion activities gained momentum with the elections in the 2000s and that emerged critical issues were transformed into social movements. By establishing ideological networks and a structure of division of labor, the progressive media converted media effects into political effects. The conversion was effectuated in the following order: (1) the Internet newspapers raise an issue and form a public argument; (2) political webzines transform the issue and the argument into subjects of sophisticated discussion; and (3) the Nosamo or other civil and social organizations apply the conclusions from the discussion in electoral campaigns or so- 
cial movements. Under such mechanism, public discussion activities and political mobilization could be carried out simultaneously. The cyclical movement was especially effective and powerful in the case of short-term issues. This aspect of the progressive media explains why the progressive camp was a major political beneficiary of the Internet and how netizens' awareness of their political effectiveness could be enhanced.

\section{The Re-structuring of the Cyber Public Sphere: Great advances of the Conservative Media}

Since the attempt to impeach President Roh, the conservative camp has made remarkable advances using cyberspace. In particular, the conservative camp has successfully challenged the cyber hegemony of the progressive camp since 2005 when the New Right groups made inroads into cyberspace. Considering that it was difficult to find any influential conservative presence in cyberspace dominated by the progressives, ${ }^{7}$ the online appearance of the conservative media meant restructuring of the cyber public sphere. The debut made by the conservative "counter-media" that are equal to those of the conservative camp and networking ties forged among the conservative media changed the political cyber landscape in Korea. The change is evidenced by quantitative indices recently released. Website rankings by sector from March 2003 to March 2006 available from rankey.com can be used to illustrate the cyber power shift. The rankings comprehensively reflect various types of indices including contents traffic data (unique visit, page view, reach rate). In addition, statistics from cyworld.com about mini-homepages of politicians can be used to supplement the data from rankey.com.

First of all, the advances made by conservatives in the category of "political webzines" are truly remarkable. Cho Gab-je's World (chogabje.com), which represents Korea's old right groups, has been continuously ranked from second to sixth since its establishment. The emergence of new political webzines was no less impressive. Since March 3, 2005, new-right.com has been ranked from second to fifth and functioned as a generator of the arguments of the New Right. Seoprise, the spokesperson website of the progressive camp, has always ranked first since its establishment. However, Freezone (freezone.co.kr), a website of the New Right camp that was established to counteract Seoprise, newly entered ranking in December 2005 and has been ranked from second to fourth since then. Other conservative political webzines include the following: Dayogi (dayogi.org), which has been ranked from sixth to ninth since October 2005, Ppan (ppan.co.kr), which has been ranked from third to sixth since January 2006, and Zzangno (zzangno.com), which has been ranked seventh to fifteenth since March 2004. Since the late 2005, from four to five conservative political webzines are ranked among top-ten political webzines. Therefore, they closely match political webzines of the progressive camp.

In the category of "websites run by politicians," Park Geun-hye of the Grand National Party (conservative) had since May 2004 competed with Yu Si-min of the Uri Party (liberal) for the top ranking status. Since May 2005, Park's website has been ranked top. Park also enjoys the largest number of fan club sites voluntarily created netizen supporters. As of June 2006, there were 50 fan club sites supporting Park. As of May 8, 2006, 67\% (83 of 124) of the Grand National Party's national assemblypeople were running their own websites and the number was higher than that of the 
Uri Party's national assemblypeople: $50.7 \%$ (72 of 142). In the top-20 ranking of the date of establishment of the website, 17 were National Assemblypeople of the Grand National Party whereas only 3 were from Uri Party. The ranking of monthly visitors was topped by Park Geun-hye's website with 166,243 visitors. The second on the ranking was Im Jong-seok of the Uri Party with only 6,295 visitors. In the case of Park's website, 100 postings per month were left in the visitors' book where as only 10 postings per month were made in Yim's website. This shows that Park's visitors were more active and committed. The rapid drop in approval ratings for President Roh and Uri Party is negatively affecting websites of Uri Party lawmakers in terms of the number of members and access rates. In the meanwhile, the websites of the Grand National Party lawmakers are profiting from political setbacks of President Roh and Uri Party.

In the "Internet newspaper" category, Dailian (dailian.co.kr), which was established to confront Ohmynews, has been ranked from eighth to tenth since its opening in March 2005. Similarly, the Independent (independent.co.kr) has kept its top-ten status since establishment. The Daily NK (dailynk.com), which is run by the Network for North Korean Democracy and Human Rights, also has been ranked about tenth since March 2005. Dailian, the Independent, and the Daily NK are waging war with the progressive media-Ohmynews and Pressian (pressian.com) - for hegemony in cyberspace.

In the categories of "NGO" and "human rights," the advance of conservative websites was similarly astounding. In the NGO category, Polizen (polizen.com) has been ranked first or second since entry in December 2005. Liberty Union (486.co.kr), which belongs to the New Right, has been ranked from first to fourth since March 2005. Citizens United for Better Society (cubs-korea.org) has been ranked from third to twelfth since March 2005. In the field of human rights, the Network for North Korean Democracy and Human Rights (nknet.org) and the Democracy Network Against North Korean Gulag (nkgulag.org) has been continuously ranked fifth on average since March 2005.

Continued social influence of mainstream newspapers (conservative) has supported the advance of the conservatives in cyberspace. In the category of "comprehensive dailies," the share of conservative sites has been overwhelming. The online versions of major newspapers - the Chosun Ilbo (chosun.com), JoongAng Ilbo (joins.com), and the Donga Ilbo (donga.com) - have continuously ranked first, second, and third. This shows that mainstream newspapers, which have a combined share of more than $80 \%$ have maintained their predominant media presence online as well as offline.

The rapid growth of the conservative media online was not only quantitative but also qualitative. Above all, the conservative media are growing as counter-media and the expansion of their influence is especially pronounced three most influential categories: political webzines, Internet newspapers, and websites of politicians. Each of the conservative websites has chosen a target among the progressive camp's websites. For instance, Freezone, Dailian, and Parksamo (parksamo.com) have respectively targeted Seoprise, Ohmynews, and the Nosamo in waging ideological struggles. Furthermore, the great leap forward of the online conservative media is affecting other fields including NGOs, human rights, and academia. Although the websites in these three fields are not significant in terms of media impact, they provide in-depth ideologies and policy alternatives. Conservative websites that lead arguments are almost 
websites of the New Right that are proponents of political new conservatism and liberal market economy values.

That the New Right camp is playing the leading role in the rapid advance of the conservative media is a remarkable facet of the ongoing change in Korea's online media. The New Right purports to transcend the Old Right and to propose ideological coordinates that can counter progressive values. In Korean society, the New Right movement functions as a counter-movement that resists social change. In other words, the New Right movement is a movement that emerged as a response to the advances made by the progressive camp, which has continuously expanded their sphere of influence during the last twenty years of the post-authoritarian era. Upon entering the establishment, the progressive camp has carried out reforms in a disruptive fashion. As a consequence, the voice of the conservatives became less influential and the society as a whole appeared to be tilting toward the left (Yi Yun-hui, 2005). Unlike the Old Right that concentrates on offline activities, the New Right has wisely used cyberspace to expand its basis for presenting conservative arguments. Major organizations that belong to the New Right include Liberty Union, Center for Free Enterprise, New Right Think Net, the Korean Hayek Society, Textbook Forum, Korean Intellectuals for Freedom, the Ahnmin Institution, Health and Society Forum, and Constitution Forum. The New Right camp is organized into three branches New Right Think Net (intellectuals), New Right Network (social movement), and New Right Foundation (movement headquarters).

An additional factor that contributed to the new balance between the progressive and the conservative camps in cyberspace is the change in ideological preferences of netizens. According to a recent survey, the age composition of politically active netizens - those who post their opinions on political and social issues to Internet bulletin boards and copy others' writings to other websites - was contrary to the conventional expectation. The most politically active netizens were in their fifties $(38 \%)$ and were followed by those in their twenties (33.5\%), thirties (28.4\%), and forties (27\%). Furthermore, comparable numbers of netizens identify themselves as either conservatives $(29.4 \%)$ or progressives $(27.7 \%)$ while a sizeable number of moderates $(42.9 \%)$ exist. $^{8}$ The result is similar to results from Gallup Korea surveys conducted in April 2004 and February 2006. During that two-year period, the share of those considering themselves as progressives dropped sharply from $33.4 \%$ to $18.9 \%$ whereas the share of conservatives was relatively constant (from $23.1 \%$ to $22.2 \%$ ). In $2006,22.2 \%$ of the general public identified themselves as conservatives whereas $29.4 \%$ of the netizens identified themselves as conservatives. Among the general public, $19.9 \%$ identified themselves as progressives whereas $27.7 \%$ of netizens identified themselves as progressives. The survey also revealed that $13.9 \%$ of conservative netizens were politically active on the Internet (posting and copying writings) whereas only $6.5 \%$ of progressive netizens were engaged in such activities. Other survey results have also shown that netizens have become increasingly. According to an analysis of Media Daum(daum.net)'s Agora, which is the largest online community for political discussions, $58.4 \%$ of postings supported the Act on National Security ${ }^{9}$ whereas $41.6 \%$ of the posting were opposed. Out of a total of 6,505 postings, 2,748 postings had more than one comment. Analysis of the first comments attached to the postings showed that $55.3 \%$ of comments $(1,519)$ were supportive of the maintenance of the Act on National Security whereas $44.7 \%$ of comments $(1,229)$ preferred abolition of the act. ${ }^{10}$ In the past, a common criticism was that public opinion in cyberspace was disproportionately represented by specific age groups and social strata; however, the surveys cited above show that progressive and conservative camps are equally represented. 


\section{The Structure of Conservative's Presence in the Cyberspace}

Online groups that espouse common ideologies or interests use Internet to share identity and to enhance their influence. In short, the network is a relational structure of interactions composed of nodes and lines. As an organism that is established by actors, the structure generates diverse values and effects (Sunstein, 2001; Park \& Jankowski, 2008). In the network, each actor is endowed with an autonomous identity and role. And because the identity and role is linked and shared by interactions, homogeneous nodes form online clusters characterized by highly dense interactions (Ritzer, 1998). Because the Internet is composed of an infinite number of links, it is efficient to pass through hubs that have many links when one wants to get access to specific websites. Therefore, a few nodes that are equipped with a large number of links function as hubs, which are pivotal parts of clusters. The hubs, which are few in number, play the following roles. First, in the cyber ecosystem called the network, the hubs function as the most important species. Second, the hubs provide the shortest links to nodes with common identity and group them into clusters. Third, as the links between clusters and the outside world, the hubs have the potential for unlimited expandability. Fourth, the hubs turn the network ecosystem from a space of disorder or arbitrariness into a phase structure that creates order and stability (Baraba'si, 2002).

\section{Figure 1. Conservative Eco-system in the Cyberspace}

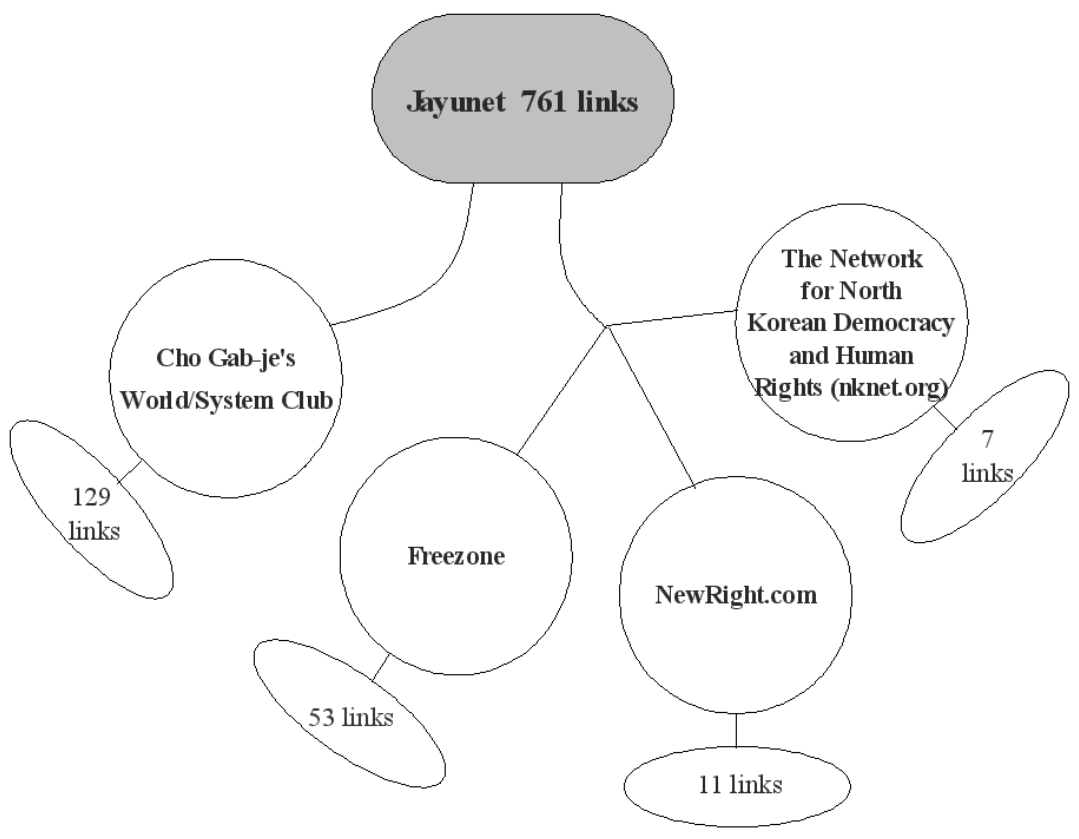

A hub's number of links is a criterion for assessing network accessibility. In this respect, the pivotal hub of conservative sites is Jayunet (Jayu.net). Jayunet functions as a "headquarters of conservative portal sites" by providing accessibility based on the extremely systematic categorization of conservative sites. In other words, Jayunet is located at the acme of the structure of the cyber public sphere. Jayunet uses a banner named "Cyber Terminal" to provide links to the fan club websites and mini-websites of major presidential candidates and regional politicians (mostly belonging to the Grand National Party). A unique function available at Jayunet is a categorization of 
761 sites - of which 27 sites are classified as leftist sites - into 24 fields, which are linked by a search engine.

Other representative hubs are Cho Gab-je's World and System Club (cafe.daum.net/systemclub). On their homepage, they placed a banner named "A Collection of Addresses of Patriotic Organizations" to link 129 conservative sites. The sites listed comprehensively represent various fields and organizations including the academia, religions, journalists, organizations and citizens' associations, North Korea, military affairs, media organizations, legal circles, education, and "anti" sites. However, Cho Gab-je's World and System Club do not provide links to New Right sites and confine themselves to Old Right sites. As of now, conservative sites that are as comprehensive, large, and systematic as Jayunet, Cho Gab-je's World, and System Club cannot be found.

Some conservative sites function as hubs of subgroups in the online conservative ecosystem. For instance, Freezone is a "conservative portal site in the field of journalism." Freezone has positioned a link box in the lower left section of its homepage to link to 53 sites categorized into media sites, political parties, political webzines, Internet newspapers, daily newspapers, and organizations. Interestingly, websites of the progressive camp are included among the linked sites. The inclusion may be intended to emphasize that the conservative and the progressive camps are on an equal footing in online pubic discussion activities. NewRightDotCom provides links to 11 core sites that have emerged as "conservative portal sites of the New Right camp." The Network for North Korean Democracy and Human Rights is a "conservative portal site specializing in North Korea" and provides links to seven sites: the Daily NK, Alliance of the Youth and Students for Human Rights in North Korea, Democracy Network Against North Korean Gulag, Database Center for North Korean Human Rights, Freedom North Korea Broadcast, Citizens' Coalition for Human Rights of Abductees and North Korean Refugees, and Radio Free Asia. Only seven in number, the sites, however, are conservative websites that play leading roles in raising North Korea-related issues from conservative perspective.

Table 1. Characteristics of Conservative Hub Sites in the Cyberspace

\begin{tabular}{lll}
\hline Pivotal hub site & $\begin{array}{l}\text { Cho Gab-je's World } \\
\text { System Club }\end{array}$ & $\begin{array}{l}\text { Freezone } \\
\text { NewRightDotCom } \\
\text { The Network for North Korean } \\
\text { Democracy and Human Rights }\end{array}$ \\
\hline $\begin{array}{lll}\text { Ideological orientation } \\
\text { Website operator }\end{array}$ & Old Right & New Right \\
Activities of linked sites & Ondividual & Organization \\
\hline
\end{tabular}

Source: Author's own research

In sum, these super-sites play central roles in consolidating the phase structure of online-based conservative ecosystem (See Figure 1). By passing through these sites, netizens can get short-cut access to all conservative websites. The phase structure has two layers. Jayunet is placed on the top. Below, Old Right sites such as Cho Gab-je's World and System Club and New Right sites such as Freezone, NewRightDotCom form clusters. That the hub of the Old Right is an individual's website whereas the hub of the New Right is an organization's website illustrates one important difference 
between the Old and the New Right. A review of the links in these hub sites also tells that organizations linked in the Old Right's hub focus on offline activities whereas those linked in the New Right's hub have strong online orientations. For this reason, conservative sites that are ranked high on the list of the cyber public sphere are in general those from the New Right.

\section{Concluding Remarks: \\ Assessing Implications of the Online Advance Achieved by the Conservatives}

The rapid growth of the online conservative media was motivated by a prevailing sense of crisis felt inside the conservative camp and the camp's strong discontentment with Roh Moo Hyun's government. From the formative years of the cyber public sphere to the present, the progressive camp won two presidential elections consecutively: the fifteenth presidential election in 1997 and the sixteenth presidential election in 2002. Furthermore, the campaign to prevent nomination and election of "ineligible" candidates in the sixteenth (2000) and the seventeenth (2004) general elections and the opposition parties' attempt to impeach President Roh have demonstrated the political power of the Internet, which was previously exploited by the progressive camp. In contrast, the conservative camp was reluctant to carry out collective response. Instead, conservative intellectuals expressed their opinions through writings such as newspaper columns. In particular, the existence of powerful representatives in the mainstream media such as the Chosun Ilbo, JoongAng Daily, and the Donga Ilbo ${ }^{11}$ made it seem unnecessary to exploit the Internet. Therefore the conservative camp tended to consider itself as a victim of cyberactivism. Recapturing power even appeared to be a remote dream for conservatives. Overcoming such pessimism, the conservative camp managed to make new advances in the cyberspace and could initiate restructuring of the cyber public sphere. The camp's success can be above all attributed to "the infection from the progressives."

Rapid increase of the conservative media and their engagement in public discussion activities take the form of ideological counterattack against the progressive camp. After the breakdown of anti-communist authoritarianism, Korea's conservative camp failed to secure an alternative ideological foundation. In contrast the progressive camp assumed initiatives for the institutionalization of democracy. As the structure of political struggle changed from "democracy vs. dictatorship" to "progressivism vs. conservatism," ideological conflict was intensified in Roh Moo Hyun's government. The conservative camp has asserted that policies implemented by Roh's government have harmed liberal democracy and the market economy. For instance, "preference for distribution rather than growth and equality rather than competition" is viewed as leftist by the conservatives who prefer the principle of "small government, large market." The conservatives are similarly dissatisfied with the policy of embracement toward North Korea and argue that a more offensive posture toward North Korea's human rights issue is necessary. Regarding Korea-US relations, the conservatives oppose the government's attempt to inaugurate a new relationship that would ensure more autonomy and argue that the traditional Korea-US relationship should be either maintained or even strengthened. 
Table 2. Ideological Conflicts in Korea's Cyber Public sphere by Issues

\begin{tabular}{|c|c|c|c|}
\hline Core issues & Old Right Camp & New Right Camp & Progressive Camp \\
\hline $\begin{array}{l}\text { Contemporary } \\
\text { Korean history } \\
\text { and developmen- } \\
\text { tal dictatorship }\end{array}$ & $\begin{array}{l}\text { Necessary choice for } \\
\text { national reconstruc- } \\
\text { tion and economic } \\
\text { development }\end{array}$ & $\begin{array}{l}\text { Balanced assessment of } \\
\text { merits and demerits of the } \\
\text { past }\end{array}$ & $\begin{array}{l}\text { Priority given to "liquidation" } \\
\text { of past history which was anti- } \\
\text { nation, anti-democratic, and } \\
\text { anti-people }\end{array}$ \\
\hline $\begin{array}{l}\text { Unification and } \\
\text { policy toward } \\
\text { North Korea }\end{array}$ & $\begin{array}{l}\text { Unification by ab- } \\
\text { sorbing North Korea }\end{array}$ & $\begin{array}{l}\text { Active provision of propos- } \\
\text { als for North Korea's de- } \\
\text { mocratization and improve- } \\
\text { ment of human rights; Pur- } \\
\text { suit of unification by trans- } \\
\text { forming North Korea into a } \\
\text { normal state }\end{array}$ & $\begin{array}{l}\text { Emphasis on the normalization } \\
\text { of South-North relations; Em- } \\
\text { bracement of North Korea and } \\
\text { coexistence }\end{array}$ \\
\hline Korea-US alliance & $\begin{array}{l}\text { Asymmetrical Korea- } \\
\text { US alliance }\end{array}$ & $\begin{array}{l}\text { Pragmatic use of Korea-US } \\
\text { alliance for the pursuit of } \\
\text { national interest }\end{array}$ & $\begin{array}{l}\text { Pursuit of national autonomy } \\
\text { that transcends existing Korea- } \\
\text { US relations }\end{array}$ \\
\hline Market economy & $\begin{array}{l}\text { State intervention for } \\
\text { growth }\end{array}$ & $\begin{array}{l}\text { Economic policies centered } \\
\text { on the market economy }\end{array}$ & $\begin{array}{l}\text { Emphasis on distribution and } \\
\text { welfare under government in- } \\
\text { tervention }\end{array}$ \\
\hline $\begin{array}{l}\text { Speed of social } \\
\text { reform }\end{array}$ & $\begin{array}{l}\text { Maintenance of the } \\
\text { existing system }\end{array}$ & $\begin{array}{l}\text { Pursuit of gradual change } \\
\text { based on national consensus }\end{array}$ & $\begin{array}{l}\text { Pursuit of radical and disrup- } \\
\text { tive changes }\end{array}$ \\
\hline
\end{tabular}

Source: Yi Yun-hui (2005).

The advances of the conservative media in cyberspace are characterized by the following characteristics in terms of "the media" and "actor." Realizing the potential of the cyber public sphere in the end depends on the extent to which "participant and interactive communication" can be vitalized. In this respect, the conservative camp is benefiting from "the advantage of backwardness" as it is learning from the strengths of the progressive media. The most representative example is conservative political webzines' benchmarking of their progressive counterparts. In the area of website menus and operational method, conservative political webzines have imitated progressive political webzines. Copying the example from Seoprise, Freezone, NewRightDotCom, and Polizen have established "Gate Column" ${ }^{12}$ sections on their homepages to post columns on major issues and to promote discussions. Furthermore, they provide independent column sections for the most representative non-gaek and their readers. Each column, to which comments are attached by readers, is used as a means for further discussion and argumentation. As in the case of progressive readers, conservative readers often copy their favorite columns and paste them in other websites. Furthermore, discussion rooms for specific topics are opened to induce discussions among netizens. Conservative political webzines have adopted scoring and recommendation systems and high quality columns written by netizens are posted in the "Gate Column" section. The conservative websites train and produce next-generation non-gaek by appointing proven netizens writers as non-gaek. ${ }^{13}$ In the case of Polizen, a homepage menu named "Link Best" was installed to post writings from other conservative political webzines. This practice, which cannot be found in progressive political webzines, shows close coalition forged inside the conservative camp.

On the other hand, it can be remarked that the advance of the conservative media is supported by the vitality of the New Right. In the mainstream of the conservative camp, the New Right is replacing the Old Right. In conservative political web- 
zines, representative writers - who could be categorized as the second-generation conservative non-gaek - generally follow the ideological lines of the New Right. In particular, many of them are ideological converts who used to be progressives in the past. For instance, Byeon Hui-jae was a non-gaek at Seoprise and led anti-Chosun Ilbo movement and campaign to support Roh Moo Hyun in the presidential election. Recently, he defected to the conservative camp and now is a representative non-gaek at Freezone, which provided Byeon with a separate column room named "Media Love." Byeon is now an active critic of Roh Moo Hyun's government. Some past leaders of progressive students' movement have participated in the establishment of Liberty Union and the Network for North Korean Democracy and Human Rights and now lead the New Right movement.

Whether the advance of the conservatives in the cyberspace means decline of the progressives is a theoretical issue that should be considered in the following two respects. First, the conservatives and progressives are undergoing different phases in the evolution of communities. As social organisms, communities go through the life cyclic phases of (1) formation, (2) maintenance, (3) development, (4) disorganization, (5) reorganization (disintegration or integration). Currently, the progressive camp, which had dominated the cyber public sphere is undergoing phases (4) and (5) whereas the late-coming conservative camp is located in phases (1), (2), and (3). In other words, the two camps intersect at a moment that is characterized by "asynchronism of synchronism." Communities, which are based on homogeneity, can be divided because of specific events and spread of heterogeneous opinions. For instance, progressive non-gaek sites went through rapid fragmentation within several months after the inauguration of Roh Moo Hyun's government. The events that affected the breakup include the issue of introducing the special prosecutor system act ${ }^{14}$ and the founding of the Uri Party. Seoprise rapidly split into "pro-Roh and Roh-neutral (Dongprise; politizen.com) and anti-Roh (Namprise; namprise.com)." The offshoot sites soon gave birth to Innermost (innermost.org) and Xinderella (xinderella.com). Similar mechanism could be also found in the case of the Nosamo where proponents of either "strengthening" or "dissolving" were opposed to each other. When the opposition parties attempted to impeach President Roh, the Nosamo briefly appeared to opt for renewed unity. However, massive defection of its members could be observed since the lowering of the approval rating for President Roh. Considering the history of progressive online media, conservative public sphere may undergo rapid fragmentation and reorganization under the influence of political events, policies, political parties, and leadership.

Second, it is uncertain whether the advance of the conservative media really points to radical reorganization and ideological consolidation of conservative values in Korean society because the advance of the conservatives may only be a reflection of lowered support for the current government. Furthermore, the conservative camp has not been creative in devising new media or methods of communication. Until now, adopting the techniques of the progressives and exploiting the technical aspects of the Internet in the ways they were exploited by the progressives ensured the success of the conservative entry into cyberspace. Finally, unlike in cyberspace, the Old Right is at the helm of the conservative movement in Korea. The future success of the conservative online media and its leadership in the public sphere will depend upon their overcoming the weaknesses that were already exposed and the extent to which they 
can successfully withstand another round of counterattacks waged by the progressive camp.

The transformation of the cyber public sphere has not been merely a Korean phenomenon. In the dimension of ideology, cyber-balkanization has been arising world-wide. In Societies with well-developed information technologies, elections and civil movements power shift has deepened cyber-balkanization. In the case of recent U.S. presidential campaign, the online conflict between progressive and conservative has been very keen. And anti-Estrada demonstrations in the Philippines in 2000 and 2001 were due to the work of progressive netizens. The transformation of the cyber public sphere will be developed fiercely, because cyberspace is a space of hegemonic competition.

\section{References}

Arendt, Hannah. (1998). The Human Condition, University of Chicago Press.

Baraba'si, Albert-La'szlo. (2002). Linked: The New Science of Networks, Cambridge: Perseus Publishing Books.

Bimber, Bruce. (2003). Information and American democracy. Cambridge University Press.

Bimber, Bruce. (1998). "The Internet and Political Transformation: Populism, Community and Accelerated Pluralism," Polity 31(1), 133-160.

Boncheck, Mark seth, Won Seong-muk(trans). (2005). From Broadcast to Netcast, Seoul: Communicationbooks.

Chang, Woo-Young. (2005a). "The Internet, Alternative Public Sphere and Political Dynamism: Korea's polemist websites," The Pacific Review 18(3), 393-415.

Chang, Woo-Young. (2005b). "Online Civic Participation, and Political Empowerment: Online Media and Public Opinion Formation in Korea," Media Culture \& Society 27(6), 925-935.

Chang, Woo-Young. (2006a). "The Structure of Political Opportunity and the Social Movement," Informatization Policy 13(3). 143-164.

Chang, Woo-Young. (2006b). "The Politics of Internet Regulation," Social science Research 14(1). 34-71.

Baraba'si, Albert-La'szlo. (2002). Linked: The New Science of Networks, Cambridge: Perseus Publishing Books.

Corrado, Anthony. (1996). "Elections in Cyberspace: Prospects and Problems," in Anthony Corrado \& Charles M. Firestone(eds), Elections in Cyberspace: Toward New Era in American Politics, Washington. D.C.: The Aspen Institute, 1-31.

Dahlgren, Peter. (1995). Television and Public Sphere. London: Sage.

Davis, R. (1999). The Web of Politics: The Internet's Impaction the American Political System. New York: Oxford University Press.

Fraser, N. (1992). "Rethinking the Public Sphere: A Contribution to the Critique of Actually Existing Democracy," in Calhoun, C(ed.), Habermas and the Public Sphere (pp. 318-331). The MIT Press.

Habermas, Jürgen. (1989). The Structural Transformation of the Public Sphere: an inquiry of bourgeois Society, Lantham: The MIT Press.

Im Hyuk-baeg. (1994). Market, the State, and Democracy. Seoul: Nanam Press. (in Korean) 
Jang Myeong-hak. (2003). "Habermas's Theory of the Public Sphere and Deliberative Democracy," Study of Korean Politics 12(2), 35-62. (in Korean)

Kahn, Richard \& Douglas, Kellner. (2004). "New Media and Internet Activism: from the 'Battle of Seattle' to Blogging," New Media \& Society 24(1), 87-95.

Keane, J. (2000). "Structural Transformation of Public Sphere," in Kenneth L. Hacker \& Jan van Dijk(ed.), Digital Democracy: issues of theory and practice ( pp. 7089). London: Sage.

Kellner, Douglas. (2001). "Intellectuals, the New Public Spheres, and TechnoPolitics." Obtained May 20, 2005 from www.gseis.ucla.edu/faculty/kellner

Kim Yong-ho. (2004). "Netizen Populism or New form of Political Participation?: A Case Study of the Nosamo," Article Presented at the Monthly Meeting of IT Politics Research Society. (in Korean)

Koreanclick. (2005). A Report on Internet Users. Seoul: Koreanclick. (in Korean)

McCaughey, Martha and Ayers, Michael D. (2003). Cyberactivism: Online Activism in Theory and Practice, London: Routledge.

Meikle, Graham. (2002). Future Active: Media Activism and the Internet, London: Routledge.

National Computerization Agency. (2006). The State Informatization White Paper. Seoul: NCA.

Newhagen, J. E. \& Levy, M. (1996). "Distributed Communication Architecture and News.” Obtained November 12, 2000 from http://www.wam.umd.edu/ $\sim$ creampuf/grape.html

Negt, O. \& Kluge, A. (1993). Public Sphere and Experience: Toward an Analysis of the Bourgeois and Proletarian Public Sphere, Minneapolis: University of Minnesota Press.

Norris, P. (2002). Democratic Phoenix. Cambridge University Press.

Oh Byeong-il and Jang Yeo-gyeong. (2003). "History and Tasks of Progressive Network Movement," Politics of Resistance, Coalition, and Remembrance, Seoul: Munhwagwahaksa. (in Korean)

Oh Yeon-ho. (2004). Special Product of Korea: Ohmynews, Seoul: Humanist. (in Korean)

Poster, M. (1998). "Cyberdemocracy: Internet and Public Sphere," in David Porter(ed.), Internet Culture, (pp. 201-218). London: Routledge.

Park, H. W., \& Jankowski, N. (2008). "A hyperlink network analysis of citizen blogs in South Korean politics," Javnost/The Public, A special issue on methodological issues in conducting online political communication research. 15(2), 57-74

Ritzer, G. (1998). Sociological Theory. NY: Alfred A. Knopf Press.

Schmidtke, Oliver. (1998). "Berlin in the Net," in Cathy Byran, Roza Tasgarousainou, Danian Tambini(eds.), Cyberdemocracy: Technology, Cities and Civic Networks. Routledge, pp. 60-83.

Schultz, T. (2000). "Mass media and the concept of interactivity: An exploratory study of online forums and reader email," Media, Culture \& Society (22), 205221.

Sunstein, C. R. (2001). Republic.Com, NJ: Princeton University Press.

The Chosun Ilbo (newspaper), May 8, 2006. (in Korean)

Trevor, Locke (1999). "Participation, Inclusion, Exclusion and Netactivism: How the Internet Invents New Forms of Democratic Activity," (pp. 211-221) in Barry N. Hague \& Brian D. Loader(eds.), Digital Democracy, London: Routledge.

46 | Journal of Contemporary Eastern Asia, Volume 7, No.2 
Viguerie, Richard. and Franke, David. (2004). America's Right Turn: How Conservatives Used New and Alternative Media to Take Power. Chicago \& LA: Bonus Books.

Yi Yun-hui. (2005). "Social Roles of Counter Social Movements: The Case of Korea's New Right Movement," Discourse 201 8(1), 5-31. (in Korean)

Yun Pyeong-jung. (2005). "The Ideology of "the Political and the Public Sphere," Philosophical Study 53, 305-325. (in Korean)

Yun Yeong-min. (1996). Theory of Electronic Information Space: Sociological Exploration of Computer Network, Seoul: Jeonyewon. (in Korean)

\section{Notes}

${ }^{1}$ As of March 2004, according to a ranking by alexa.com, there were 24 conservative and 11 progressive sites listed in the top 10,000 US websites. Of the ideological sites, conservative sites were ranked from first to fourth (Drudge Report, World Net Daily, News Max, LewRockwell), whereas Salon, a progressive site, was ranked fifth. Following Salon, conservative sites were ranked from sixth to fourteenth. Challenging MoveOn.org, a hub of progressive sites, RightMarch.com, with a self-appointed mission to become a portal site of conservatives was established. Viguerie, Richard. and Franke, David (2004).

${ }^{2}$ Since its liberation in 1945 from Japanese Occupation and the US military government, Korea was ruled by a succession of authoritarian governments until the transition to democracy in 1987. In particular, oppressive rule by the military lasted for four decades from 1961, the year of the first military coup d'état. During the period, state-led industrialization progressed rapidly. In exchange of authoritative rule, democracy was suppressed. The critical event that terminated the long-lasting authoritarian rule was the "June Uprising" of 1987. In 1987, students, citizens, and a coalition of opposition parties demanded direct presidential election in large-scale demonstrations. Yielding to the popular demand, the military began to split. In the end, transition to democracy began as the moderates in the military agreed to the implement the popular demand (Im Hyuk-baeg, 1994).

${ }^{3}$ The speed of informatization in Korea has been extremely fast. Korea has led the information age in the areas of Internet availability and the number of Internet users. As of 2005, more than 31 million people out of the total population of 47 million have access to very high speed Internet. More than 12 million Koreans are subscribers to very high-speed Internet services. Korea is ranked top in the following criteria: availability of personal computers by household (more than $83 \%$ ), the availability of very high speed Internet connection, the number of Internet cafes, dotcom registration by countries, and the amount of online stock exchange (Koreanclick, 2005) As of 2006, Korea is ranked first in terms of digital opportunity index, fifth in national informatization index, first in e-government readiness index, and sixth in technology infrastructure for national competitiveness (National Computerization agency, 2006).

${ }^{4}$ Chollian, Hitel, Naunuri, and Unitel were four major PC communication companies in the 1980s and 1990s.

${ }^{5}$ Sisa Journal is a representative weekly publication in Korea and Media Today is a publication for media review published by the National Union of Mediaworkers.

${ }^{6}$ The Nosamo is an online fan club of Roh Moo Hyun that was created by his supporters when Roh, a candidate of the Millennium Democratic Party, failed to be elected in the fourteenth and the fifteenth National Assembly election because of the barrier of regionalism. When the organization was established in May 2000, there were about 500 members. Within a year, the membership increased to more than 4,000. The organization expanded its activities to the offline world and the membership reached about 50 thousand in August 2002. In December 2002, at the time of the presidential election, the Nosamo's membership surpassed 100 thousand people. For its members, Roh Moo Hyun was the symbol of political reform in Korea and an agent for overcoming regionalism in Korea. Thanks to the Nosamo's successful online mobilization strategy in the party preliminary in which citizens could participate in, Roh, who was a minor candidate, was nominated as the presidential candidate of the Millennium Democratic Party. Far from being discouraged by a division in the party and Roh's low popularity in comparison with the presidential candidate of the Grand National Party, the Nosamo established a special committee for the presidential election and carried a strategy that linked online and offline networks. The Nosamo thus made decisive contribution to Roh's victory in the presidential election.

${ }^{7}$ Until 2002, in rankey.com's ranking by sector, only Cho Gab-je's World and the Independent were the only conservative media ranked in the top-ten list. rankey.com is Korea's leading Internet ranking 
site comparable to alexa.com.

${ }^{8}$ This is a result that Korea Internet Politics Research obtained by commissioning a survey to pollever.com, an online survey company. From April 10 to 14, 2006, the survey was made to 1,500 netizens. The numbers were adjusted to reflect the shares of Internet users by age groups. The following is the breakdown of Korean netizens: 6-19 (9150; 27.7\%), 20-29 (7600; 23.0\%), 30-39 (8090; $24.5 \%), 40-49$ (5690; 17.2\%), 50-59 (1750; 5.3\%), more than 60 (730; 2.2\%). The Chosun Ilbo, May 8, 2006.

${ }^{9}$ This act is the most representative act that restricts citizens' political rights. The act has been maintained on the ground that North-South Korea conflict necessitates the act. For several decades, the conservatives have argued for its maintenance whereas the progressive have demanded its revision or abolition.

${ }^{10}$ From December 2004 to April 2006, Korea Internet Politics Research carried out an analysis of 6505 postings at Agora. Agora's Issue Discussion Room is famous for being a space where the most active discussions by netizens are made. Various types of issues - social, political, current affairs, etc. - are discussed at the online section. The Chosun Ilbo May 8, 2006.

${ }^{11}$ They are Korea's three major newspapers that occupy $75-80 \%$ of newspaper sales in Korea. Especially, the Chosun Ilbo is Korea's oldest and the most influential daily newspaper. At the same time, the newspaper is the most conservative. Since the transition to democracy, it was perceived as a leading medium critical towards reformist government In addition to anti-reformist tendency, hereditary management of the paper invited criticism on the part of the government, which cited the paper as the number target of media reform. Since the end of the 1990s citizen's organizations have systematically organized anti-Chosun movements.

12 "Gate Column" is the most important menu in political webzines. In this section, columns on the most hotly debated issues are posted. Netizens participate in fierce discussions surrounding the issues presented by columns.

${ }^{13}$ On the history political webzines, and their current operational status and structure of conflict in Korea, see Chang (2005b).

${ }^{14}$ While in office, former President Kim Dae-jung met North Korea's Kim Jong Il, the chairman of North Korea's National Defense Commission, to pursue his unification policy. The summit meeting has been viewed as a historic event in Korea's half-century history of tragic division. After the inauguration of Roh's government, however, the Grand National Party argued that a large sum of money was secretly sent to the North by former President Kim's government and demanded an investigation into the matter by the special prosecutor system. Facing an offensive from the Grand National Party, the Millennium Democratic Party was sharply divided between a group supporting Roh Moo-hyun and the other group supporting Kim Dae-jung. In the end, Roh agreed to the argument of the Grand National Party and the pro-Roh faction left the Millennium Democratic Party to found the Uri Party. 